\title{
Novas Aquisições para a Próxima Geração de Stents Coronarianos
}

\author{
Áurea J. Chaves
}

E sta edição traz, entre excelentes manuscritos, dois artigos que tratam de novas opções para a próxima geração de stents coronarianos, que incorporam alterações destinadas a eliminar a trombose tardia dos stents farmacológicos.

O artigo de revisão de Brito, Costa e Abizaid enfoca os stents bioabsorvíveis, tecnologia que já está dando seus primeiros passos na direção da próxima geração dos stents coronarianos. Com a proposta de "desaparecer" depois de cumprido seu papel de sustentar a parede do vaso durante a fase de cicatrização e com isso não deixar hastes expostas ao fluxo sanguíneo, além de permitir a restauração da motilidade normal do vaso tratado, a expectativa é de que o problema da trombose tardia do stent seja resolvido. Alguns modelos já foram testados clinicamente e demonstram que o principal obstáculo a ser vencido é manter a força radial do stent, caracteristicamente menor que o stent metálico, e evitar a retração crônica da parede, responsável por parte da perda da luz do vaso na fase final de cicatrização. A alternativa que parece mais promissora no momento é a incorporação de antiproliferativos à matriz polimérica, compensando, com a esperada redução da hiperplasia intimal, parte da perda da luz em decorrência da retração do vaso. A tomografia de coerência óptica, realizada durante o estudo angiográfico na fase tardia da evolução e ilustrada na capa deste fascículo, mostra imagens inéditas das hastes de um stent de policarbonato em momentos diversos do processo de reabsorção, seis meses após o implante.

O artigo original de Chamié et al. traz o desempenho de um novo stent liberador de sirolimus, em que o polímero durável foi trocado por uma nanocobertura de hidroxiapatita microporosa, mais biocompatível, que regula a liberação do antiproliferativo. Resultados iniciais demonstram supressão marginalmente inferior da hiperplasia intimal, quando comparado ao stent Cypher, com potencial ganho na segurança tardia, a ser confirmado em coortes maiores de pacientes. Editorial de Byrne e Kastrati, do Deutsches Herzzentrum, Technische Universität, em Munique, Alemanha, discute magistralmente todas as opções do desenvolvimento de plataformas de stents farmacológicos sem polímero permanente, com foco no stent testado
VESTAsync. Analisa as respostas supressoras da hiperplasia intimal desse novo stent nos dois momentos avaliados e faz interessantes colocações a respeito da cinética de liberação do sirolimus e a eficácia do stent.

Outros estudos avaliam aspectos variados do desempenho dos stents na ampla gama de utilização dessas próteses. Contribuição do Registro DESIRE analisa os resultados clínicos de longo prazo de seus pacientes com lesões de baixa complexidade (on-label), comparados àqueles de pacientes com lesões mais complexas (off-label), tratados com stents farmacológicos. O grupo off-label, que representou mais de três quartos da população examinada, mostrou, ao final do período de seguimento clínico de quase três anos, probabilidade de $90 \%$ de os pacientes estarem livres de eventos cardíacos adversos. Brito Jr. e Caixeta, do Hospital Israelita Albert Einstein, São Paulo, e da Columbia University Medical Center e Cardiovascular Research Foundation, Nova York, respectivamente, lembram em seu editorial que os questionamentos relativos à segurança e à eficácia desses dispositivos nas situações offlabel são atenuadas hoje em dia, face à constatação de equivalência dos porcentuais de óbito e infarto entre os stents farmacológicos e não-farmacológicos e a nítida vantagem dos primeiros em reduzir a reestenose. Enfatizam, no entanto, a necessidade da individualização do tratamento baseado no consenso dos especialistas, para a obtenção dos melhores resultados para esses pacientes com anatomias mais complexas.

Quadros et al., do Instituto de Cardiologia do Rio Grande do Sul, em Porto Alegre, exploram os limites mecanísticos do implante de stents coronarianos, ao avaliar se esses stents implantados de forma mais agressiva (fenômeno do step-up, step-down), para alcançar maiores diâmetros luminais, influenciam o prognóstico de pacientes com síndrome coronariana aguda sem supradesnivelamento do segmento ST. Echeverri e Cabrales, do Serviço da Fundação Cardiolnfantil Instituto de Cardiologia, em Bogotá, Colômbia, com grande conhecimento do tema, e tendo por base estudos experimentais muito bem fundamentados, já publicados na Revista Brasileira de Cardiologia Invasiva, revisam em seu editorial as relações entre intensidade do trauma arterial causado pelos diferentes instrumentais de dilatação e a resposta reparadora vascular. 
Outra contribuição significativa relata resultados do tratamento endovascular dos aneurismas e dissecções da aorta por Alves et al. Trata-se de uma publicação da Escola Paulista de Medicina, de São Paulo, uma das instituições com maior experiência no tratamento tanto percutâneo como cirúrgico dessas afecções da aorta, em que a autora principal, com profundo conhecimento do assunto, não só mostra de forma clara os resultados como faz reflexões relacionadas à seleção de pacientes, com o intuito de reduzir a mortalidade desse grupo de altíssimo risco para eventos adversos. Fabio Jatene, do Instituto do Coração, em São Paulo, um dos expoentes em nosso meio no tratamento cirúrgico das doenças da aorta, comenta em seu editorial a falta de estudos que comparam os diferentes tratamentos desses pacientes, lembra o contínuo desenvolvimento das próteses endovasculares, agora na terceira geração, com menor perfil e maior flexibilidade, e saúda a apresentação desses resultados, muito importantes para o aprimoramento do método.

Fugindo da temática dos trabalhos que avaliam resultados de tratamentos, o artigo especial de Queiroga Lopes et al. analisa em profundidade as principais controvérsias para a incorporação dos stents farmacológicos no Brasil em seus aspectos éticos e jurídicos. Complementa o tema análise muito equilibrada e abalizada de Carlos Gottschall, do Instituto de Cardiologia do Rio Grande do Sul, em Porto Alegre, que faz uso de sua vasta erudição para ressaltar que diversos fatores, como a evidência científica disponível, a experiência do profissional e os possíveis riscos e custos, devem ser considerados na escolha dos stents.

Finalizando, gostaríamos de dar as boas-vindas aos novos integrantes do Conselho Editorial, profissionais que muito têm contribuído para elevar ainda mais o nível científico de nossa Revista: os cirurgiões cardiovasculares Domingo Braile e Fabio Jatene, os cardiologistas clínicos Carísi Polanczyk e Luis Henrique Gowdak, e os cardiologistas intervencionistas Alcides Zago, Carlos Gottschall, Claudia Rodrigues Alves, Darío Echeverri, Francisco Chamié, Gilberto Nunes, Jorge Pinto Ribeiro, Maurício Barbosa, Samuel Silva da Silva e Valmir Fontes.

Áurea J. Chaves

Editora 